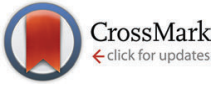

Cite this: Chem. Commun., 2016, 52,12865

Received 8th August 2016,

Accepted 1st October 2016

DOI: $10.1039 / c 6 c c 06490 f$

www.rsc.org/chemcomm

\section{Alkaline-earth phosphonate MOFs with reversible hydration-dependent fluorescence $\dagger$}

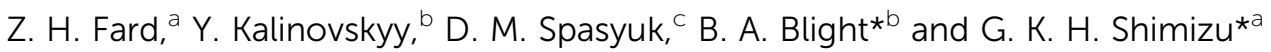

\begin{abstract}
A new rigid tritopic phosphonic ligand, 2,4,6-tris(4-phosphonophenyl)pyridine $\left(\mathrm{H}_{6} \mathrm{~L}\right)$, was synthesized and used to assemble isostructural barium (1) and strontium (2) phosphonate metal organic frameworks that exhibit fully reversible and selective water-dependent fluorescence red-shift at room temperature.
\end{abstract}

Since the first reports in 1978 by Alberti of the layered metal phosphonates, ${ }^{1}$ research on phosphonate-based metal organic frameworks (MOFs) has expanded mainly due to their thermal stabilities and extremely low solubility. ${ }^{2}$ These robust materials have been engineered for multiple applications including proton conductivity, ${ }^{3}$ optics, ${ }^{4}$ catalysis, ${ }^{5}$ sorption, ${ }^{6}$ and ion exchange ${ }^{7}$ making the rational design and synthesis of metal phosphonates with novel architectures and properties increasingly important. At present, there are few examples of phosphonate-ligated architectures with heavier alkaline-earth (AE) metal ions, ${ }^{3 d, 8}$ despite the benefits of the pliant $\mathrm{AE}$ coordination sphere in accessing single crystals via hydrothermal or solvothermal techniques. Beyond structure, interest in the emissive properties of heavy AE-containing MOFs has emerged with work by Manos and Lazarides, ${ }^{8,9}$ who demonstrated yellow emission of the MOF upon exposure to water. This is notable as reports of water sensing MOFs are infrequent, ${ }^{8-10}$ and only a single report exists of a sufficiently sensitive response to demonstrate a spectral shift by varying relative humidity rather than direct wetting ${ }^{11}$

Herein, we present two isostructural MOFs, $\mathrm{M}_{4}\left(\mathrm{H}_{2} \mathbf{L}\right)_{2}\left(\mathrm{H}_{2} \mathrm{O}\right)_{x}$. $\left(\mathrm{H}_{2} \mathrm{O}\right)_{y}(\mathrm{M}=\mathrm{Ba}, \mathrm{Sr} ; \mathbf{1}, 2$ respectively), prepared with a new trigonal phosphonate ligand $\left(\mathbf{H}_{6} \mathbf{L}\right.$, Fig. 1). We report on the

\footnotetext{
${ }^{a}$ Department of Chemistry, University of Calgary, Calgary, Alberta T2N 1N4, Canada.E-mail: gshimizu@ucalgary.ca

${ }^{b}$ School of Physical Sciences, University of Kent, Canterbury, CT2 7NH, UK. E-mail: b.blight@kent.ac.uk

${ }^{c}$ Canadian Light Source, 44 Innovation Blvd., Saskatoon, Saskatchewan, S7N 2V3, Canada

$\dagger$ Electronic supplementary information (ESI) available: Supporting TGA, SEM, gas sorption, fluorescence emission, PXRD, and diffuse reflectance data, as well as synthetic and NMR data are provided. CCDC 1497928. For ESI and crystallographic data in CIF or other electronic format see DOI: 10.1039/c6cc06490f
}

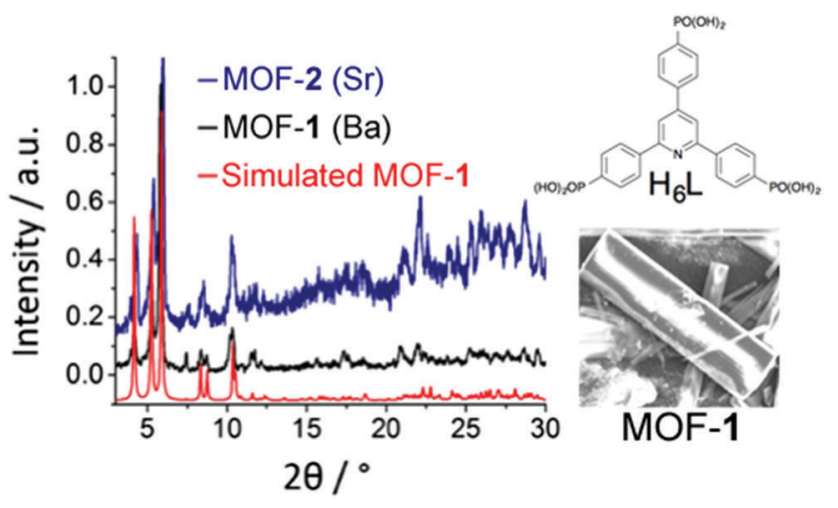

Fig. 1 Simulated and experimental PXRD patterns of MOF 1 (red and black), experimental PXRD pattern of MOF $\mathbf{2}$ (blue), structure of ligand $\mathbf{H}_{6} \mathbf{L}$, and SEM picture of the single crystals of 1 .

preparation of the ligand and the synthesis, structural characterization and solid state luminescent properties of $\mathbf{H}_{6} \mathbf{L}$ and both MOFs 1 and 2. Both MOFs exhibit bright green fluorescence at room temperature upon immersion.

The synthesis of $\mathbf{H}_{6} \mathbf{L}$ was achieved in good yield by phosphorylation of 2,4,6-tris(4-bromophenyl)pyridine ${ }^{12}$ via the Michaelis-Arbuzov reaction. ${ }^{13}$ Other MOF materials with other trigonal phosphonate ligands have been reported. ${ }^{3 e, 14}$ MOFs 1 and 2 were then synthesized via solvothermal reaction of $\mathbf{H}_{\mathbf{6}} \mathbf{L}$ and either $\mathrm{BaBr}_{2}$ or $\mathrm{Sr}(\mathrm{OH})_{2}$ in $\mathrm{DMF} / \mathrm{H}_{2} \mathrm{O}$ mixed solvents sealed in $23 \mathrm{~mL}$ Teflon-lined autoclaves at $120{ }^{\circ} \mathrm{C}$ for $48 \mathrm{~h}$. Colourless platelike single crystals of 1 were obtained after $48 \mathrm{~h}$. Compound 2, however, formed a microcrystalline phase that precluded single crystal characterization. Detailed experimental procedures are presented in the ESI. $\uparrow$ The powder X-ray diffraction (PXRD) patterns of bulk samples of $\mathbf{1}$ and $\mathbf{2}$ matched simulations from the single crystal of 1 (Fig. 1).

The structure of 1 is an extended 3D framework (monoclinic $C 2 / c$ ) built up from the linkage of one-dimensional $\mathrm{BaO}$ columns, running down the $b$-axis, by the organophosphonate $\mathbf{H}_{2} \mathbf{L}$ ligand. The $\mathrm{N}$ atom of the pyridine ring is disordered over three sites with 

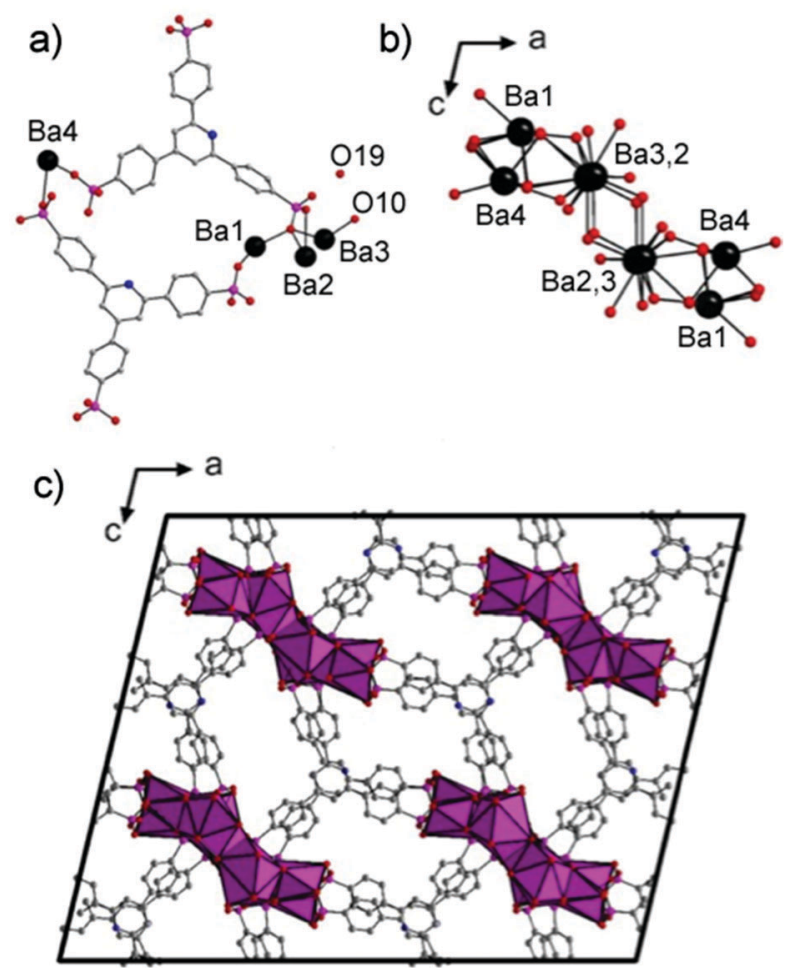

Fig. 2 (a) Asymmetric unit in 1. Hydrogen and disordered atoms are omitted for clarity; (b) $\mathrm{Ba}_{6} \mathrm{O}_{44}$ unit in 1 along $b$ axis; (c) packing of the compound 1 along crystallographic $b$ axis with polyhedral representation of $\mathrm{Ba}_{6} \mathrm{O}_{44}$ cluster. Lattice water molecules and disorder are omitted for clarity.

the $\mathrm{C}-\mathrm{H}$ groups. The asymmetric unit has four crystallographically distinct Ba sites, two $\mathbf{H}_{2} \mathbf{L}$ ligands, a $\mu-2$ coordinated $\mathrm{H}_{2} \mathrm{O}(\mathrm{O} 10)$ and one lattice $\mathrm{H}_{2} \mathrm{O}$ molecule (O19) (Fig. 2a). The Ba1 atom is coordinated to nine phosphonate $\mathrm{O}$ atoms from six ligands. The $\mathrm{Ba} 2$ is ten-coordinated with nine phosphonate $\mathrm{O}$ atoms of five ligands and one water molecule. $\mathrm{Ba} 3$ is nine-coordinated with eight $\mathrm{O}$ atoms of five ligands and one water molecule. $\mathrm{Ba} 4$ coordinates nine phosphonate $\mathrm{O}$ atoms from six ligands. Face-sharing $\mathrm{BaO}$ polyhedra form a $\mathrm{Ba}_{6} \mathrm{O}_{44}$ (stoichiometrically) one-dimensional column along the $b$ axis (Fig. 2b) that bridge equivalent units through twelve ligands (Fig. 2c). The result is a 3-D MOF with 1-D hydrated channels $(\sim 7.2 \times 10.9 \AA$, interatom) along the $b$ axis (Fig. 2c).

Thermal stability of MOFs 1 and 2 was tested by thermogravimetric analysis (TGA) (Fig. S3 and S4, ESI $\dagger$ ). MOF 1 showed a first weight loss of $8.1 \%$ below $150{ }^{\circ} \mathrm{C}$, attributable to the loss of eight water molecules (seven lattice, one coordinated; calcd: $7.5 \%$ ). At $\sim 160{ }^{\circ} \mathrm{C}$, there is a second weight loss of $8.2 \%$, likely loss of two DMF molecules (calc. 8.2\%). The solvation from TGA cannot be compared with the crystallographic formula since most lattice solvent molecules were highly disordered and removed from the refinement (see ESI $\dagger$ ). TGA, however, correlated very well with the elemental analysis data (Fig. S3 and S4, ESI $\dagger$ ). MOF 2 showed a similar TGA profile with elemental analysis in agreement with TGA data.

MOFs 1 and 2 were also examined for porosity (Fig. S5, ESI $\dagger$ ). Both are non-porous towards $\mathrm{N}_{2}$ at $77 \mathrm{~K}$. They both showed low
$\mathrm{CO}_{2}$ uptake (about $0.86 \mathrm{mmol} \mathrm{g}^{-1}$ ) at $1200 \mathrm{mbar}$ and $273 \mathrm{~K}$. Upon repeated exposure to moisture, both MOFs gradually lose long range order (Fig. S18 and S19, ESI $\dagger$ ), however, as will be discussed, this does not mean a loss of interesting optical properties. Indeed, in this case, the ability of water to access the coordination sphere, is critical to the sensing properties. These features will be shown to be reversible for multiple cycles, indicating that while long range is compromised, the local structure is retained.

Upon exposure to UV light, these materials showed obvious emission properties, and thus we assessed the solid-state luminescence spectra of the free $\mathbf{H}_{6} \mathbf{L}$ ligand, and MOFs $\mathbf{1}$ and $\mathbf{2}$ at room temperature. The ligand displays broad fluorescent emission at $\lambda_{\mathrm{em}}=421 \mathrm{~nm}\left(\lambda_{\mathrm{em}} 402 \mathrm{~nm} ;\right.$ Fig. S8, ESI $\left.\dagger\right)$ with a modest quantum yield $(\Phi=0.072)$. The emission is likely derived from $\mathrm{n} \rightarrow \pi^{*}$ and $\pi \rightarrow \pi^{*}$ electronic transitions. MOFs 1 and 2 exhibit red-shifted emission bands as compared to $\mathbf{H}_{6} \mathbf{L}$, with bright aqua-blue emission in its dehydrated (dried) state (1: $\lambda_{\mathrm{em}}=$ $448 \mathrm{~nm} ; 2: \lambda_{\mathrm{em}}=489 \mathrm{~nm}$ ) (both $\lambda_{\mathrm{ex}}=408 \mathrm{~nm}$ ) in the solid-state (Fig. S8 and S12, ESI $\dagger$ ). Upon coordination to the AE ions, cationic withdrawing effects result in the bathochromic shift that we attribute to metal-perturbed intra-ligand charge transfer ( $\mathrm{n} \rightarrow \pi^{*}$ and $\pi \rightarrow \pi^{*}$ ), as distances between the layered $\pi$-systems (>4 $\AA$ ) are beyond $\pi$-stacking distances, precluding inter-ligand CT. In addition to the red-shift, both networks also display slight increase in quantum efficiency $(\Phi=0.099$, and 0.087 for $\mathbf{1}$ and 2 respectively). The $42 \mathrm{~nm}$ disparity in emission maxima between MOF 1 and 2 is consistent with the differing charge densities of the coordinated metal ions $\mathrm{Ba}$ and $\mathrm{Sr}^{8}{ }^{8}$

Most interestingly, when MOFs 1 and 2 were treated with liquid water the colour of the solids change from a white powder to bright yellow, while the fluorescence behaviours of each compound exhibit red-shifted emission into the green region at $505 \mathrm{~nm}$ and $522 \mathrm{~nm}$, respectively (Fig. $3 ; \lambda_{\mathrm{ex}}=408 \mathrm{~nm}$ ). Furthermore, under wet conditions, the quantum efficiencies of MOFs 1 and 2 nearly double to $\Phi=0.16$ and 0.14 , respectively, in the solid-state (outlined in Table S1, ESI†). Upon drying the MOFs at $70{ }^{\circ} \mathrm{C}$ under vacuum, both display near fully

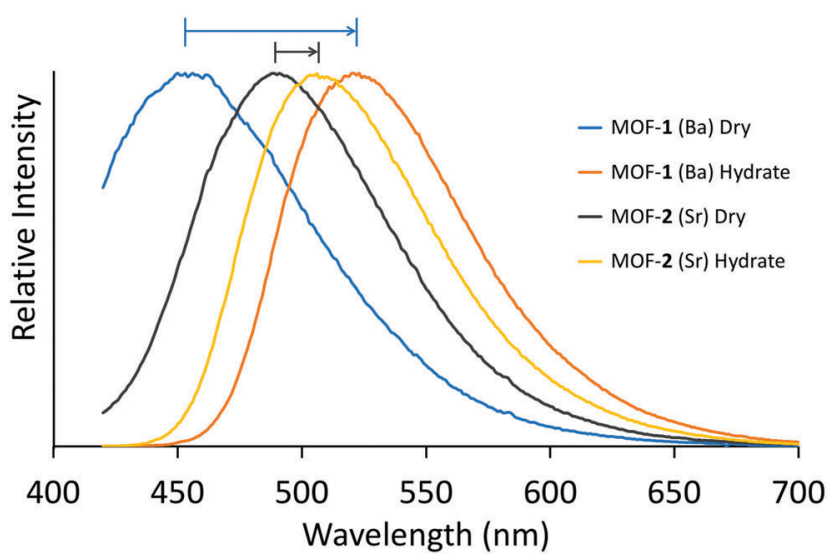

Fig. 3 Solid state fluorescence spectra $\left(\lambda_{\text {ex }}=408 \mathrm{~nm}\right)$ of as-prepared MOF 1 (dry, blue; wet, orange), and MOF 2 (dry, black; wet, yellow) at room temperature. 
reversible blue-shifted emission. A hydration study was also performed on the free ligand in both solution (Fig. S23 and S24, ESI $\dagger$ ) and the solid state, however no change in emission was observed. We tested the selectivity of this emission response and, surprisingly, no other polar-protic or polar-aprotic solvents perturbed the system at all. To check the hydration dependence on emission, luminescence measurements were also performed on MOFs 1 and 2 upon exposure to 30, 40, 50, and 85\% relative humidity. Under these conditions, MOF-1 did not show any changes in the emission maxima. However, upon reaching $100 \%$ humidity, the emission band red-shifted dramatically to $\lambda_{\text {max }}=529 \mathrm{~nm}$ (Fig. S16, ESI $\dagger$ ). For MOF-2, we observed a gradual red-shifting upon increasing humidity (Fig. S17, ESI $\dagger$ ) showing the sensitive response.

We further assessed the reversibility of the sensing response of these MOFs. These studies clearly show the change in emission is not correlated to the extent of crystallinity. Each solid was dried in a vacuum oven to ensure dehydration. Upon exposure to water vapour in a humidity chamber regulated to $100 \%$ humidity, we saw the described redshift and subsequent blueshift upon re-dehydration. We further cycled this process two more times to demonstrate the complete reversibility of this process with little degradation of the respective emission signals (Fig. 4a). PXRD (Fig. S18 and S19, ESI $\dagger$ ) illustrates that the hydrate phases of MOFs $\mathbf{1}$ and $\mathbf{2}$ do not fully retain crystallinity upon drying. This is further evidence that the emission profiles of the dehydrated MOFs are not discretely linked to ordered ligand arrangements within the crystalline phase thus precluding inter-ligand charge transfer as relaxation pathway. The ability of water to easily access the coordination sphere of the $\mathrm{AE}$ ions facilitates the sensing response but sacrifices crystallinity. Thus, the sensing ability of these systems hinges
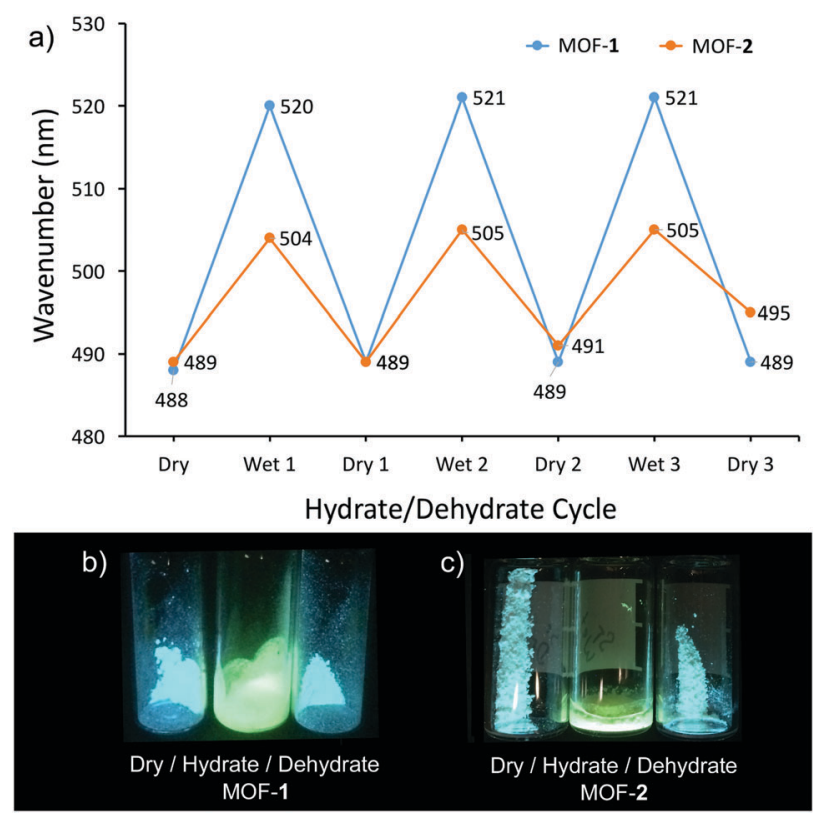

Fig. 4 (a) Demonstration of reversible emission response in the presence and absence of water; (b) colour change of MOF-1 in response to hydration; (c) colour change of MOF-2 in response to hydration. on the short range structure and not linked to the retention of long range order. We posit that the observed colour change (both absorption and emission) suggests hydration of the metal cluster, and enacts a significant enough change in the coordination environment to (a) lose crystallinity, and (b) allow the ligands to engage disordered $\pi$-stacking interactions. This is further supported by the fact that the coordination arch of $\mathrm{Ba}^{2+}$ is larger, giving rise to a more malleable network structure in MOF 1, which results in a more prominent re-shift than MOF2 containing $\mathrm{Sr}^{2+}$ due to its ability to form stronger inter-ligand $\pi$-interactions.

In summary, two new phosphonate MOFs are reported with a new ligand, 2,4,6-tris(4-phosphonophenyl)pyridine, $\mathbf{H}_{\mathbf{6}} \mathbf{L}$. MOFs $\mathbf{1}$ and $\mathbf{2}$ exhibit a hydration-dependent fluorescence red-shift at room temperature in the solid-state. For MOF 2, this change occurs even in the presence of a humid environment. The sensing is selective to water. It was shown that uptake and loss of water molecules are accompanied by fully reversible changes in the photoluminescence spectra even though PXRD shows loss of long range order. This latter point is significant given the weight placed on retention of crystallinity in MOF research in assessing function.

\section{Notes and references}

1 G. Alberti, U. Costantino, S. Allulli and N. Tomassini, J. Inorg. Nucl. Chem., 1978, 40, 1113-1117.

2 (a) G. K. H. Shimizu, R. Vaidhyanathan and J. M. Taylor, Chem. Soc. Rev., 2009, 38, 1430-1449; (b) K. J. Gagnon, H. P. Perry and A. Clearfield, Chem. Rev., 2012, 112, 1034; (c) G. K. H. Shimizu, J. M. Taylor and K. W. Dawson, Metal Phosphonate Chemistry: From Synthesis to Applications, Royal Society of Chemistry, 2012, vol. 15, p. 493; (d) K. Maeda, Microporous Mesoporous Mater., 2004, 73, 47-55.

3 (a) G. Alberti and M. Casciola, Solid State Ionics, 1997, 97, 177-186; (b) S. Kim, K. W. Dawson, B. S. Gelfand, J. M. Taylor and G. K. H. Shimizu, J. Am. Chem. Soc., 2013, 135, 963-966; (c) P. Ramaswamy, N. E. Wong, B. S. Gelfand and G. K. H. Shimizu, J. Am. Chem. Soc., 2015, 137, 7640-7643; (d) M. Bazaga-García, R. M. P. Colodrero, M. Papadaki, P. Garczarek, J. Zoń, P. Olivera-Pastor, E. R. Losilla, L. León-Reina, M. A. G. Aranda, D. Choquesillo-Lazarte, K. D. Demadis and A. Cabeza, J. Am. Chem. Soc., 2014, 136, 5731; (e) S. Pili, S. P. Argent, C. G. Morris, P. Rought, V. Garcia-Sakai, I. P. Silverwood, T. L. Easun, M. Li, M. R. Warren, C. A. Murray, C. C. Tang, S. Yang and M. Schröder, J. Am. Chem. Soc., 2016, 138, 6352-6355; $(f)$ Z.-S. Cai, S.-S. Bao, X.-J. Wang, Z. Hu and L.-M. Zheng, Inorg. Chem., 2016, 55, 3706-3712.

4 (a) S. Fan and L. Zhu, Inorg. Chem., 2007, 46, 6785-6793; (b) J. Mao, Coord. Chem. Rev., 2007, 251, 1493-1520; (c) S. Ying and J. Mao, Cryst. Growth Des., 2006, 6, 964-968; (d) L. A. Vermeulen, J. L. Snover, L. S. Sapochak and M. E. Thompson, J. Am. Chem. Soc., 1993, 115, 11767-11774; (e) L. A. Vermeulen and M. E. Thompson, Nature, 1992, 358, 656-658.

5 (a) M. Pramanik, M. Nandi, H. Uyama and A. Bhaumik, Catal. Sci. Technol., 2012, 2, 613-620; (b) B. Wan, R. G. Anthony, G. Z. Peng and A. Clearfield, J. Catal., 1986, 101, 19-27; (c) H. Byrd, A. Clearfield, D. Poojary, K. P. Reis and M. E. Thompson, Chem. Mater., 1996, 8, 2239-2246; (d) D. Deniaud, B. Schollorn, D. Mansuy, J. Rouxel, P. Battioni and B. Bujoli, Chem. Mater., 1995, 7, 995-1000.

6 (a) A. U. Ortiz, A. Boutin, K. J. Gagnon, A. Clearfield and F.-X. Coudert, J. Am. Chem. Soc., 2014, 136, 11540; (b) N. Hermer and N. Stock, Dalton Trans., 2015, 44, 3720; (c) P. L. Llewellyn, M. GarciaRates, L. Gaberová, S. R. Miller, T. Devic, J.-C. Lavalley, S. Bourrelly, E. Bloch, Y. Filinchuk and P. A. Wright, J. Phys. Chem. C, 2015, 119, 4208; (d) M. T. Wharmby, J. P. Mowat, S. P. Thompson and P. A. Wright, J. Am. Chem. Soc., 2011, 133, 1266-1269.

7 (a) A. Clearfield, Mater. Chem. Phys., 1993, 35, 257-263; (b) A. Clearfield, Solvent Extr. Ion Exch., 2000, 18, 655-678; (c) J. D. Wang, A. Clearfield 
and P. Guang-Zhi, Mater. Chem. Phys., 1993, 35, 208-216; (d) G. Cao, H. G. Hong and T. E. Mallouk, Acc. Chem. Res., 1992, 25, 420-427.

8 A. Douvali, G. S. Papaefstathiou, M. P. Gullo, A. Barbieri, A. C. Tsipis, C. D. Malliakas, M. G. Kanatzidis, I. Papadas, G. S. Armatas, A. G. Hatzidimitriou, T. Lazarides and M. J. Manos, Inorg. Chem., 2015, 54, 5813-5826.

9 A. Douvali, A. C. Tsipis, S. V. Eliseeva, S. Petoud, G. S. Papaefstathiou, C. D. Malliakas, I. Papadas, G. S. Armatas, I. Margiolaki, M. G. Kanatzidis, T. Lazarides and M. J. Manos, Angew. Chem., Int. Ed., 2015, 54, 1651-1656.

10 (a) Y. Yu, J.-P. Ma and Y.-B. Dong, CrystEngComm, 2012, 14, 7157-7160; (b) Y. Yu, X. M. Zhang, J.-P. Ma, Q.-K. Liu., P. Wang and Y.-B. Dong, Chem. Commun., 2014, 50, 1444-1446.
11 F. Drache, V. Bon, I. Senkovska, M. Adam, A. Eychmüller and S. Kaskel, Eur. J. Inorg. Chem., 2016, 4483-4489.

12 J. A. Mikroyannidis, S. Ye and Y. Liu, Synth. Met., 2009, 159, 492-500. 13 R. A. Dhokale and S. B. Mhaske, Org. Lett., 2013, 15, 2218-2221.

14 (a) R. Vaidhyanathan, A. H. Mahmoudkhani and G. K. H. Shimizu, Can. J. Chem., 2009, 87, 247-250; (b) R. K. Mah, M. W. Lui and G. K. H. Shimizu, Inorg. Chem., 2013, 52, 7311-7313; (c) M. Taddei, F. Costantino, R. Vivani, S. Sabatini, S.-H. Lim and S. M. Cohen, Chem. Commun., 2014, 50, 5737-5740; (d) R. K. Mah, B. S. Gelfand, J. M. Taylor and G. K. H. Shimizu, Inorg. Chem. Front., 2015, 2, 273-277; (e) A. Kondo, T. Satomi, K. Azuma, R. Takeda and K. Maeda, Dalton Trans., 2015, 44, 12717. 